\title{
Jiangping Zhou* \\ Evidentiality and other types readjusted: Interpersonal modality revisited
}

https://doi.org/10.1515/jwl-2021-0011

Received June 8, 2021; accepted September 14, 2021; published online December 29, 2021

\begin{abstract}
Interpersonal modality, bifurcating modalization and modulation, is an important construct of interpersonal meaning in the architecture of Systemic Functional Linguistics. By meticulously reviewing relevant studies from the perspectives of traditional modality and modality's semantic map, three respects with respect to the system of interpersonal modality have been supplemented. Firstly, modalization, being subcategorized into possibility and usuality, is suggested to entertain evidentiality from the traditional sense. Secondly, considering the delicacy of the system of interpersonal modality, possibility in modalization should be further categorized into epistemic and root possibility; necessity as one subtype of modulation, superseding the original obligation in modulation, is subclassified into obligation and permission; inclination, being the other subtype of modulation, should be specified as the superordinate of volition and ability. Thirdly, the shifting of modal meanings from root possibility to epistemic possibility in modalization and from inclination to necessity in modulation should be clearly specified as far as language evolvement is concerned.
\end{abstract}

Keywords: epistemicity; evidentiality; interpersonal modality; Systemic Functional Linguistics

\section{Introduction}

Interpersonal modality in Halliday's sense $(1985,1994)$ is an important concept in interpersonal metafunction, which is one of the three metafunctions: ideational, interpersonal, and textual. The ideational metafunction construes our experience; the interpersonal metafunction enacts the relationships between interlocutors; and the textual metafunction organizes a text coherently and cohesively. English modality, by and large, has been abundantly investigated during the 20th century. Major studies concerning English modality could be profiled to three different

\footnotetext{
*Corresponding author: Jiangping Zhou, School of Foreign Languages, Peking University, Beijing, China; and School of Foreign Languages, China West Normal University, Nanchong, China, E-mail: zhoujp@pku.edu.cn
} 
schools if those sporadic ones are excluded: traditional modality (cf. Larreya 2009; Palmer 1986, 2001, 2003; Portner 2009; Salkie 2009), modality in semantic maps (cf. Fan 2014, 2017; van der Auwera and Plungian 1998), and modality in Systemic Functional Linguistics (hereafter SFL) (cf. Feng 2011; Halliday 1985, 1994; Halliday and Matthiessen 2004, 2014; Li 2001, 2004). After reviewing their features and subcategories, similarities and differences between these schools are compared subsequently. By so doing, a new system of interpersonal modality in the framework of SFL is proposed to entertain the following two italicized elements into the system of interpersonal modality exemplified in Examples (1) and (2).

(1) Boris can get by with sleeping $5 \mathrm{~h}$ a night. (van der Auwera and Plungian 1998: 80)

(2) Well Schaeffer, it seems had just found the latest article from the Smithsonian. (Chafe 1986: 268)

Can in Example (1) is employed to denote the ability of the agent Boris of the clause; it seems in Example (2) provides the speaker with a source of evidence that Schaeffer had just found the latest article from the Smithsonian. However, the two italicized elements, denoting modal meanings, could be hardly expounded by the present system of interpersonal modality, indicating the necessity of revising the system in SFL.

This paper is outlined by the analysis of modality in traditional sense in Section 2, and then modality in semantic map is profiled in Section 3, which precedes the probing of interpersonal modality in SFL in Section 4; finally, the system of interpersonal modality is revisited in Section 5 before a conclusion is drawn in Section 6.

\section{Modality in the traditional sense}

Modality in the traditional sense is delimited to studies that are not investigated from the perspectives of SFL or modality in the semantic map. Traditionally, Modality has been defined in various ways (e.g. Larreya 2009; Palmer 1986, 2001, 2003; Portner 2009), but the most acceptable one is from Palmer, who defined it as "Modality is concerned with the status of the proposition that describes the event" (Palmer 2001: 1). As far as the classification of the system of modality is concerned, there is a unanimous agreement that it is composed of two sub-categories: propositional modality and event modality. The former is further subcategorized into epistemic modality and evidential modality, although evidentiality, which refers to "the grammatical marking of the source of evidence for a proposition" (DeLancey 2001: 369), is not clearly expounded in Palmer (1986); the latter subcategory is bifurcated into deontic modality and dynamic modality. The main categories can be glossed as in Figure 1. 


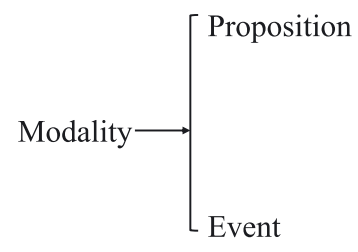

Figure 1: System of modality - main categories.

\subsection{Propositional modality}

In modal logic, propositional modality refers to the participants' attitude towards the truth-value or factual status of the proposition (Palmer 2001). It is further subcategorized into epistemic modality and evidential modality, and the two subtypes demonstrate certain differences in that speakers, with epistemic modality, tell the factual status of the proposition, while they, with evidential modality, provide the evidence for the modal value of the proposition. The detailed enunciation of epistemic and evidential modality is exemplified by the following examples.

(3) John must be in the office. (Palmer 2001: 25)

(4) John must be home already; I see his coat. (Sweetser 1990: 49)

(5) You have to stay home tonight, because I say so. (Smith 2003: 244)

(6) I saw Annie pull the trigger. (Roque 2019: 354)

(7) That one said, "He harvested his father Barentin's manioc [without permission].” (Roque 2019: 360)

Italicized parts in Examples (3) and (4) denote epistemic possibility. Must in Example (3) expresses the speculative sense in epistemic modality (Speculative in Figure 2) because judgment of the proposition John is in the office is based on John's assumption (Assumptive in Figure 2); however, must in Example (4) is deductive, because the proposition John is home already is grounded upon the deduction of the speaker's utterance I see his coat (Deductive in Figure 2). The sense of evidentiality is excluded here because what I want to foreground is the epistemic meaning. The modal meaning of epistemic necessity is realized by have to in Example (5). Epistemic modality contains senses of possibility and necessity, which is echoed by van der Auwera and Plungian (1998). This perspective will be 
illustrated in detail while discussing the semantic map in the next section. The proposition Annie pulled the trigger in Example (6) is projected by the sensory clause I saw (Sensory in Figure 2), which provides the speaker with the evidence that Annie performed the action of pulling the trigger. In Example (7), the projected proposition He harvested his father Barentin's manioc [without permission] is a direct report of the projecting verbal process said (Reported in Figure 2), thus the locution is evinced in a very high degree of possibility. As a matter of fact, both italicized parts in Examples (6) and (7) are metaphorical expressions according to Halliday's interpersonal metaphor of modality (Halliday 1985, 1994; Halliday and Matthiessen 2004, 2014). As metaphorical expressions preclude the scope of this paper, they will be skipped over while considering the area.

Up to now, the system of modality can be presented as in Figure 2.

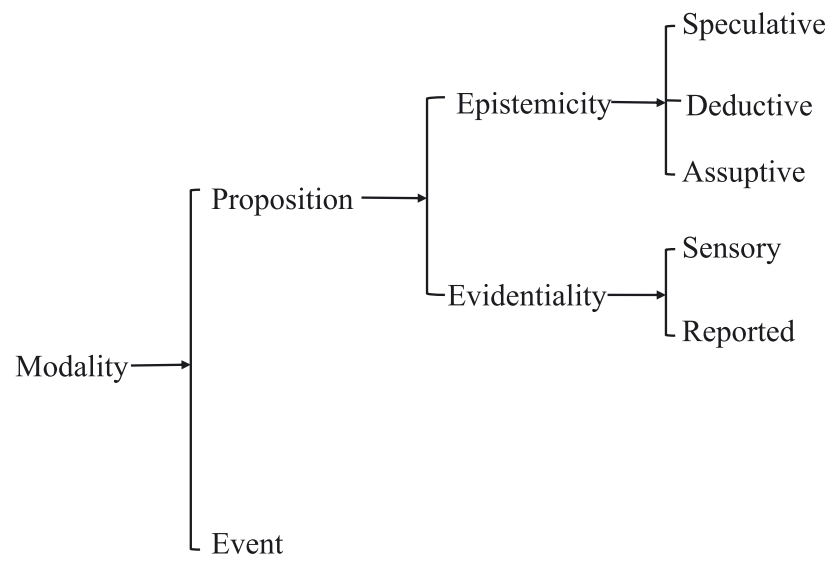

Figure 2: System of modality - propositional modality.

It seems that the system of evidentiality in Figure 2 is not exhaustive enough. Fortunately, Chafe (1986), Anderson (1986), and some other scholars, who sympathized with Chafe's ideas and explored cross-linguistic evidentiality (cf. Faller 2017; Lau and Rooryck 2017; McCready and Ogata 2007), have devoted themselves to the study of evidentiality and thus made the framework with more delicacy. They claim that knowledge of evidence forms a cline with the most reliable evidence at one pole and the most unreliable one at the other. The intermediate degrees of the cline are belief, induction, hearsay, and deduction. The sequential order does not imply that a belief is the most reliable or a deduction is the least reliable, or even induction and hearsay lie somewhere in between. The status of reliability among them is unstable in that they can move up and down the scale of the cline. Consider the following examples (italics is mine). 
(8) I think that a lot of the time I've been misjudging her. (Chafe 1986: 266)

(9) This is clearly seen if we compare the rights which legatees obtained. (BNC)

(10) I saw Annie pull the trigger. (Roque 2019: 354)

(11) I hear Mary won the prize. (Anderson 1986: 274)

(12) I heard from other people yesterday that your father said (you) go home tomorrow. (Aikhenvald 2015: 264)

(13) Adults presumably are capable of purely logical thought. (Chafe 1986: 269)

Example (10), rewritten from Example (6), and Examples (11) and (12) are more or less in accordance with Palmer's (2001) sensory and reported evidentials. I think in example (8) is gradually losing the identity of being a mental process and is grammaticalized as a modal marker expressing a certain degree of evidence. Thus, it serves as the speaker's belief that I have been misjudging her a lot of the time. Different from the modal marker in Example (8), the evidential marker, realized by an adverbial element clearly in Example (9), signals an inference accompanying a higher degree of reliability than that carried by I think in Example (8). However, presumably in Example (13) serves as a hypothesis from which a tentative conclusion may be deduced specifically in academic writing, yet it is also a measure of avoiding responsibility for evidence.

Therefore, the system of modality with the supplement of evidentiality can be rewritten as in Figure 3. These bidirectional arrows among the five subtypes of evidential modality explicate that the degree of reliability is mutable and interchangeable while the one between reliable and unreliable is a matter of cline of knowledge.

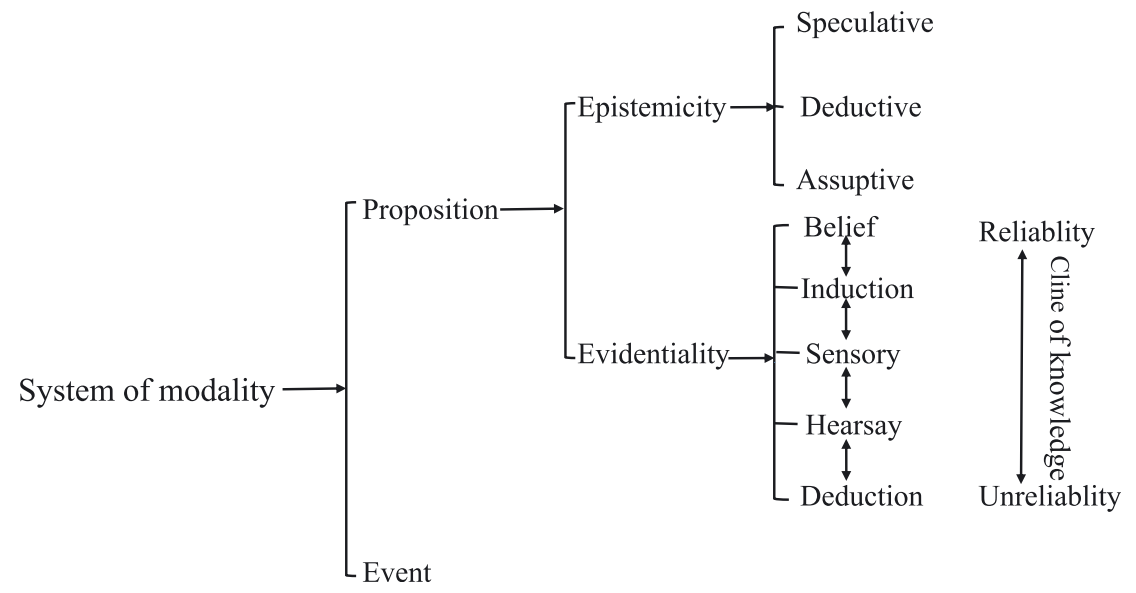

Figure 3: System of modality - evidentiality revised. 


\subsection{Event modality}

Event modality, according to Palmer (2001), refers to the event that has not been realized, or the event that has not occurred yet, but possesses the potentiality to occur. Many other linguists (e.g. Fan 2001; Leech 2013), while exploring the properties of primary modals (e.g. can, must, should, may, might, etc.) and quasimodals (e.g. have to, be supposed to, need to, etc.), sympathize with Palmer's classification of event modality into deontic modality and dynamic modality (e.g. Leech 2013). Deontic modality is defined by Lyons (1977) as a kind of association between the responsibility carrier and the necessity or possibility of implementing an action. Lyons' definition of Deontic modality is sided by Palmer and he further expounds that Deontic modality imposes a direction to the action or state of the event (Palmer 1986, 1990, 2001). Thus, the imposed force is carried out by the participant at issue. For instance, speakers in Examples (14) and (15) are exerting a minor force (their status might be unequal or even higher than the participants being addressed to) to the participants involved in the activity or they receive the permission of leaving from the speakers. The difference between the two lies in that the latter clause is more explicitly and objectively uttered than the former one; in other words, Example (15) is the noncongruent expression (to be more specific, the interpersonal metaphor of modality) of the congruent one in Example (14) in Halliday's sense of grammatical metaphor. The degree of direction in Examples (16) and (17) is much higher than that in Examples (14) and (15). The externalized obligatory force from the speakers is imposed upon the participants in these two clauses, which are also demarcated by principles employed by the former pair of expressing permissions in Examples (14) and (15).

(14) You may go now. (Palmer 2001: 20)

(15) All people are agreed here that you leave at once. (Fan 2001: 151)

(16) You should go now. (Palmer 2001: 20)

(17) The conclusion can hardly be avoided that you leave here at once. (Fan 2001: 151)

Another type of deontic modality conveyed by speakers is commission or determination, by which speakers are demonstrating their determination of performing a specific action. The widely applied deontic modal markers of this category are the primary modal shall and the quasi-modal be determined to. In the same way, the externalization of the determination is acquired from the speaker to the participant in the clause, considering italicized parts in Examples (18) and (19). There are 
special cases that the speaker conflates the participant in the clause if the subject is the first person $I$ as in Example (20) or the speaker is included as one of the participants if the subject is the plural first person We as in Example (21).

(18) You shall do as you are told. (Palmer 2001: 20)

(19) Trump said that his administration was determined to "prevent such tragedies from befalling innocent people at the hands of regimes that do not respect the rule of law or basic human decency". (COCA_Business Insider)

(20) Still, I was determined to come up with a title to let audience members know this wasn't going to be the typical how-to-get-published session. (COCA_Chronicle of Higher Education)

(21) We will use the voices and perspectives represented in the report as a guide for the future. Success in competition is important, but not at the expense of an athlete's health and safety. We are determined to do better. (COCA_New York Post)

The other category of event modality is dynamic modality (cf. Palmer 1990; Zhu 2005), which denotes a sense of volition (e.g. the quasi-modal be willing to) and ability (e.g. the primary modal can). These dynamic modal markers, to some extent, are peripheral in expressing modal meanings compared with the other primary or quasi-modal markers, because the senses of volition and ability are mainly characterized by grammatical subjects and can hardly be associated with the speaker. In other words, participants of clauses are internalized and function as the carriers of denoting the modal meanings. However, they should not be disregarded out of the system of modality, because they share semantic and/or syntactic features with other modal markers in the system of modality and their meanings are sometimes indispensable with each other. For example, the modal marker can denotes a sense of ability and deontic permission as well, and hence a clear boundary cannot be pronounced without taking into consideration the context (consider Example (22) that both ability and permission readings are possible). The dynamic ability of can in Example (23) is foregrounded while it is the deontic permission that is expressed in Example (24). Furthermore, can't in Example (25) (the negation of can) is an epistemic modal marker and the only legal form of expressing the possibility of the negative meaning of must. Besides these properties aforementioned, dynamic modalities provide the environment or serve as the source for the other two categories (deontic and epistemic modalities) to be 
derived from. More information about this evolution of modal meanings will be supplied in the third section.

(22) I can take the bag.

(23) I think the bag is too heavy for you, but I can take the bag.

(24) My brother says: "I can take the bag, if I really need it."

(25) [... [b]ut I can't do you love and rhetoric without the blood. (BNC)

Within the domain of dynamic ability, it is also necessary to demarcate the inherent ability and the acquired ability. It is the inherent ability to perform the action of $I$ in Example (26); however, the ability to bring stress and strain to a partnership in Example (27) is acquired in later intercourse with the circumstance.

(26) MRS. JEWKES: He is my master and if he bids me do anything I can do I think I ought to do it and let him who has power to command me look to the lawfulness of it. (BNC)

(27) But it's a way of life which Julie admits can bring stress and strain to a partnership. (BNC)

Therefore, if event modality is supplied to Figure 3, it can be further reconstructed as in Figure 4.

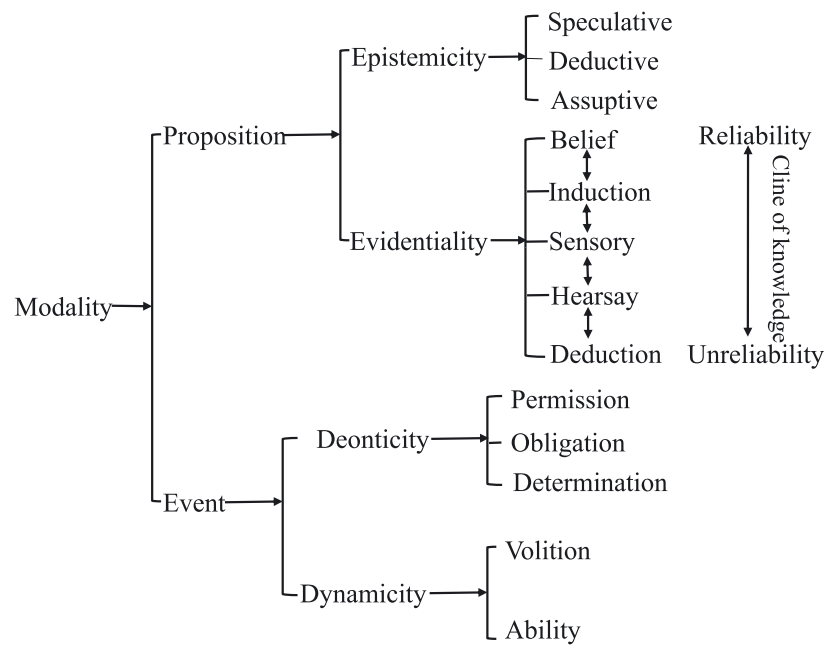

Figure 4: System of modality - event modality supplied. 


\section{Modality in the semantic map}

Modality in the semantic map is initially discussed by van der Auwera and Plungian (1998) and further revisited in the paper "Acquisitive Modals" (van der Auwera et al. 2009). Based on their discussions, the preliminary model of the semantic map is established. Later on, Fan $(2014,2017)$ has expanded the previous model after exploring linguistic features in Chinese. Accordingly, the present model of the semantic map is confirmed at length.

\subsection{The preliminary model of semantic maps}

van der Auwera and Plungian (1998: 79) defined the semantic map as "a representation of cross-linguistically relevant synchronic and diachronic connections between modal, pre-modal, and post-modal meanings or uses". Semantic map focuses on the vagueness of meanings between possibility and necessity, language evolution from possibility to necessity or vice versa, premodal etymons and post-modal meanings derived from possibility and necessity, and the demodalization of non-epistemic modality, especially the participant-internal modality or dynamic modality. Precisely, the focus of this research is upon modality in the semantic map of English and the revision of the semantic map is based on the study of Chinese. According to van der Auwera and Plungian (1998) and van der Auwera et al. (2009), modality is employed for semantic domains that include possibility and necessity as constructing a paradigm of two possible choices. They mainly categorize modality into four sub-domains: participant-internal modality, participantexternal modality, deontic modality, and epistemic modality.

\subsubsection{Participant-internal modality}

Participant-internal modality is concerned with a kind of possibility or necessity internal to the participants pertaining to the state of affairs. Possibility is dealt with participants' physical or psychological ability, and necessity is usually associated with participants' internal needs. In Example (28), the physical ability of the participant $I$ is internal, regardless of its later acquisition; while in Example (29), the internal need of the participant's having a cup of coffee enacts the ensuing function. 
(28) I can swim.

(29) I have to have a cup of coffee, otherwise I can't function. (van der Auwera et al. 2009: 273)

\subsubsection{Participant-external modality}

Participant-external modality refers to, according to van der Auwera and Plungian (1998), the externalization of circumstantial elements to the participant in the state of affairs, which is made either possible or necessary by these circumstances. Two famous examples from van der Auwera and Plungian (1998: 80) in this respect are widely quoted as in Examples (30) and (31). It is the bus 66 in Example (30) that functions as the external circumstance to make the proposition, i.e. to get to the station, possible. Similarly, the external circumstance of the bus 66 becomes a necessary means of transportation to carry the hearer to the station.

(30) To get to the station, you can take bus 66.

(31) To get to the station, you have to take bus 66 .

(van der Auwera and Plungian 1998: 80)

\subsubsection{Deontic modality and epistemic modality}

Deontic modality and Epistemic modality are more or less similar to the concepts in Palmer's system of modality, so it is unnecessary to reiterate the two terms specifically (cf. Section 2). However, the deontic modality in the sense of semantic map is a special case in participant-external modality, that is to say, the former serves as the hyponym while the latter as the superordinate. Deontic modality enables the speaker or social norms as circumstantial elements to permit and obligate the participants to be involved in the state of affairs. The term internal-participant modality, as van der Auwera and Plungian (1998) expounds, is more cumbersome and periphrastic than a single word, but it contrasts with the term externalparticipant modality, which cannot be condensed into a single word in present glossary system. More importantly, it immediately relates itself to the internalparticipant senses of possibility and necessity.

The full preliminary model of the semantic map is drawn as Figure 5, and diagramed into Figure 6. 


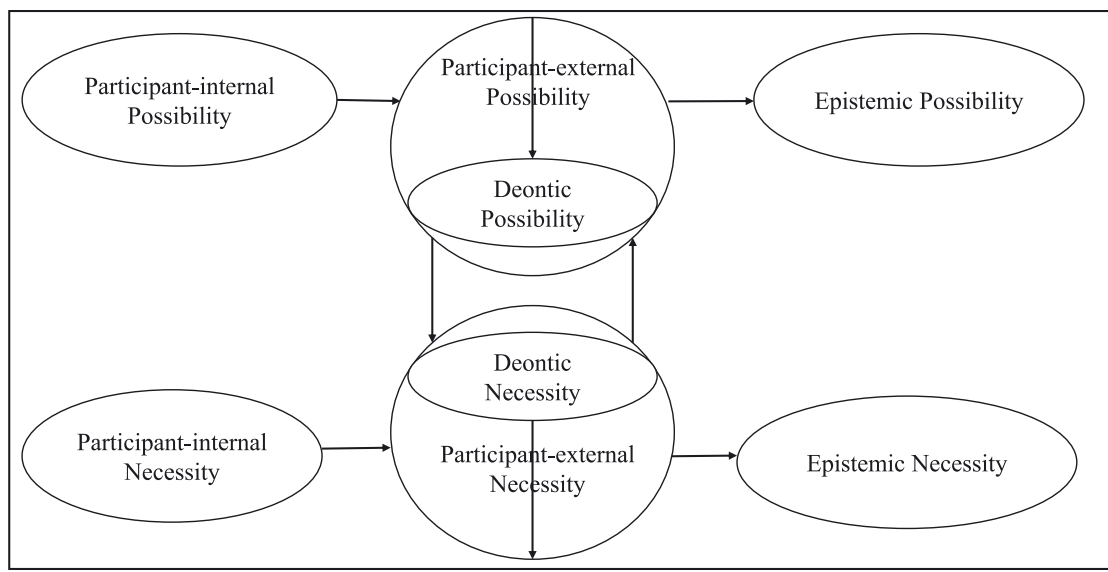

MODAL SPACE

Figure 5: The full preliminary model of the semantic map (van der Auwera et al. 2009).

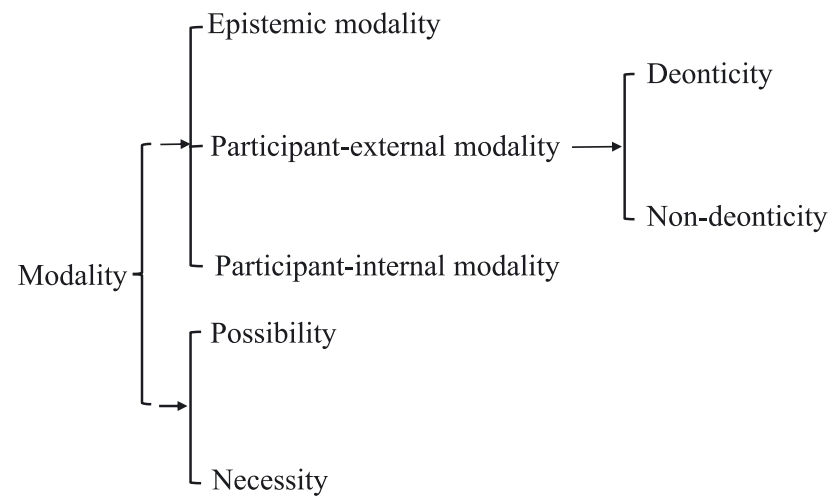

Figure 6: The preliminary modal of semantic maps.

\subsection{The revised model of the semantic map}

By employing Palmer's (2001) concepts and principles of sub-classification of modality, Fan (2014) revised the previous model of semantic map in terms of the modal possibility. Her new model of modal possibility is presented in Table 1. According to Fan (2014, 2017), the possibility of dynamic modality is further subcategorized into internal ability and conditional possibility. The former refers to the realistic objective possibility which is determined by the participants' internal 
conditions, either physically or intelligently. The latter refers to the fact that participants' external state of affairs determines the realistic objective possibility; in other words, the action of the activity is conditioned. The possibility of deontic modality encompasses conditional permission, which refers to the participants' external conditions that determine the relative force or appropriateness of the realistic state of affairs, and deontic permission or societal permission (societal permission is preferred for its clear distinction to the superordinate 'deontic modality'), which is associated with social conditions, such as the speakers' order or authority, social norms, and moral canons that are employed to decide the force or legality of the state of affairs. The possibility of epistemic modality is the speakers' subjective assumption of the affairs unjustified, or the possibility is subjectivized.

Table 1: New model of modal possibility (Fan 2014).

\begin{tabular}{|c|c|c|c|}
\hline Basic types & Possibility & Examples & Major types \\
\hline \multirow[t]{2}{*}{ Dynamic modality } & Internal ability & $\begin{array}{l}\text { He can drive the car. } \\
\text { He can move the big box. }\end{array}$ & Event \\
\hline & Conditional possibility & $\begin{array}{l}\text { The door's unlocked, so he may } \\
\text { escape inside the house. } \\
\text { You may get to the mountain by } \\
\text { bus } 331 \text {. }\end{array}$ & \\
\hline \multirow[t]{2}{*}{ Deontic modality } & Conditional permission & $\begin{array}{l}\text { You may go to the US by ship. } \\
\text { To go to the mountain, you can } \\
\text { take bus } 331 \text {. }\end{array}$ & \\
\hline & Societal permission & $\begin{array}{l}\text { According to the law, girls may } \\
\text { get married by the year of } 20 \text {. } \\
\text { According to the law of the com- } \\
\text { pany, smoking is allowed here. }\end{array}$ & \\
\hline Epistemic modality & Epistemic possibility & He may be in the office now. & Proposition \\
\hline
\end{tabular}

Note: The examples in column three are translations from Fan's (2014) Chinese examples.

Definitions and classifications of the basic types of modality proposed by Fan (2014) are, of varying degrees, different from those by Palmer (2001). Furthermore, there is a significant difference in sub-categorizing the dynamic and deontic modalities between Fan (2014) and van der Auwera et al. (2009). In Fan's model of modal possibility, she separates non-deontic modality in the preliminary model of the semantic map into conditional possibility and societal permission. Conditional possibility is assigned with an independent status out of the participant-external possibility of non-deonticity and it, together with internal ability, is subsumed to dynamic modality, which is one of the basic types of modality. Societal permission and deontic permission fall into the domain of deontic modality. 
If necessity of modality (the other category of the system of modality), together with possibility of modality enunciated above, is considered, Fan's (2014) revision of the preliminary model of the semantic map can be constructed as Figure 7.

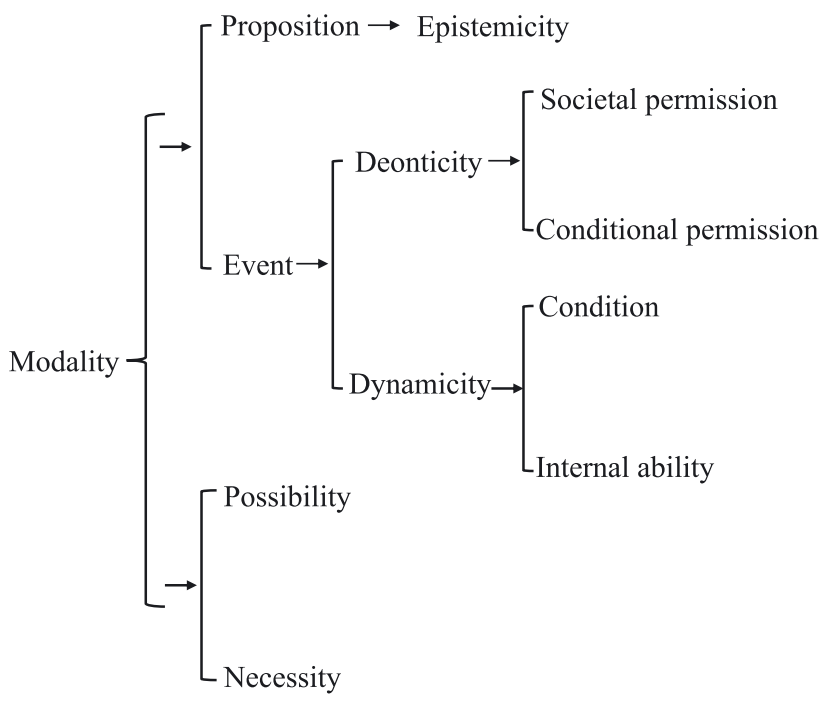

Figure 7: Revised model of the semantic map.

\section{System of modality in SFL}

Modality in SFL is primarily explored by Halliday (1970), and further advanced by him systematically (Halliday 1985, 1994). Actually, the system of modality in SFL is fully-fledged in his treatise An introduction to functional grammar and remains more or less the same or very little information has been supplied to the original system to expand its scope although the treatise has been revised several times (cf. Halliday 1994; Halliday and Matthiessen 2004, 2014). Scholars, both home and abroad, who have conducted studies on modality (e.g. Feng 2011; He and Zhang 2019; Huang and Wang 2021; Singh 2019) or interpersonal metaphor of modality (Tanverniers 2018; Yang 2013; 2018) under the guiding framework of SFL, have drawn on sufficiently the system of modality propounded by Halliday. According to Halliday $(1985,1994)$ and Halliday and Matthiessen $(2004,2014)$, the system of modality is constructed in four different aspects: polarity, value, orientation, and modality. Polarity and modality will be discussed in the following section and the discussion of value and orientation will be briefly profiled subsequently. 


\subsection{Polarity and modality in SFL}

Polarity is defined as a pair of opposition between two opposite poles of a cline, being either positive or negative. Positivity (It is. Do that!) and negativity (It isn't. Don't do that!) are located at the end of each pole (Halliday 2014). Halliday (1985, 1994) further points out that the different degrees of indeterminacy between positivity and negativity can be termed as Modality, which is sub-classified into possibility, usuality, obligation, and inclination. The former two subtypes are incorporated into modalization which expresses the truth value of a proposition, while the latter two subtypes are covered by modulation because the modal meanings are either obligatory or inclined. Possibility can be realized by modal auxiliaries as exemplified in Example (32), modal adjuncts in Example (33), or even combination of the two in Example (34). Consider the following examples:

(32) [T]hat will be John, he'll sit there all day.

(33) [T]hat's probably John, he usually sits there all day.

(34) [T]hat'll probably be John, he'll usually sit there all day.

(Halliday and Matthiessen 2014: 177)

Realization of Usuality is mainly achieved by modal adjuncts and occasionally by the primary modal verb will. There is little evidence, in present-day English, showing that other modal auxiliaries can be employed to realize Usuality. This phenomenon of Usuality realized by modal adjuncts and primary modals is exemplified in Examples (35) and (36) respectively.

(35) [It] always happens. (Feng 2011: 3)

(36) [H]e'll sit there all day. (Halliday and Matthiessen 2014: 117)

The modal meaning of Obligation is achieved by adopting primary modals and quasi-modals (e.g. have to and need to), and very rarely modal adjuncts (e.g. necessarily and obligatorily). The Inclination is solely realized by the modal auxiliary can when it is employed to express the modal meaning of ability, and quasi-modals such as be willing to, be determined to. Examples (37) and (38) suffice to explicate the phenomena in this respect.

(37) He can stand on his head without using his hands. (Nuyts and van der Auwera 2016: 34)

(38) I'm determined to win. (Feng 2011: 3) 
Significantly, Halliday regards the alternative realization of modal meanings by means of projecting clauses as interpersonal metaphor of modality, which is more advanced than the previous two approaches (Sections 2 and 3) to the study of modal meanings. Consider italicized parts in Examples (39) and (40). Projecting clauses I think in Example (39) and It is possible in Example (40) are regarded as typical cases of interpersonal metaphor of modality.

(39) I think they've forgotten about this meeting. (Nuyts and van der Auwera 2016: 47)

(40) It is possible that it is raining. (Feng 2011: 4)

\subsection{Value and orientation in SFL}

Value and orientation are sporadically examined by scholars (e.g. Palmer 2001; van der Auwera et al. 2009; Verhulst et al. 2013), but none of them discusses the two concepts within the scope of system of modality. Value in SFL is explored by Halliday and Matthiessen (2014) according to the gradability of the modal meanings which is categorized into median and outer. The outer value could be either high or low. As a matter of fact, the value of modal meanings from high degree modals to low ones forms a continuum. Orientation in SFL refers to participants' beliefs or attitudes towards a particular subject, being either subjective or objective. Furthermore, subjectivity could be articulated either explicitly or implicitly, and so could be objectivity. Table 2 demonstrates the relationship between subjectivity and objectivity with the exemplification of the expression of possibility.

Table 2: Expression of possibility (Halliday and Matthiessen 2014: 689).

\begin{tabular}{llll}
\hline Category & & Type of realization & Example \\
\hline Subjective & (a) Explicit & I think, I'm certain & I think Mary knows \\
& (b) Implicit & will, must & Mary'll know \\
Objective & (a) Implicit & probably, certainly & Mary probably knows \\
& (b) Explicit & it's likely, it's certain & It's likely Mary knows \\
\hline
\end{tabular}

Martin and Rose (2005) have explored the intermediate degrees in value and orientation topologically, which focuses on the proximity or likeness of meanings. Figure 8 treats with exemplar clauses value and orientation as two intersecting clines, in which the vertical axis denotes various degrees of values and the horizontal axis denotes different degrees of subjectivity. 


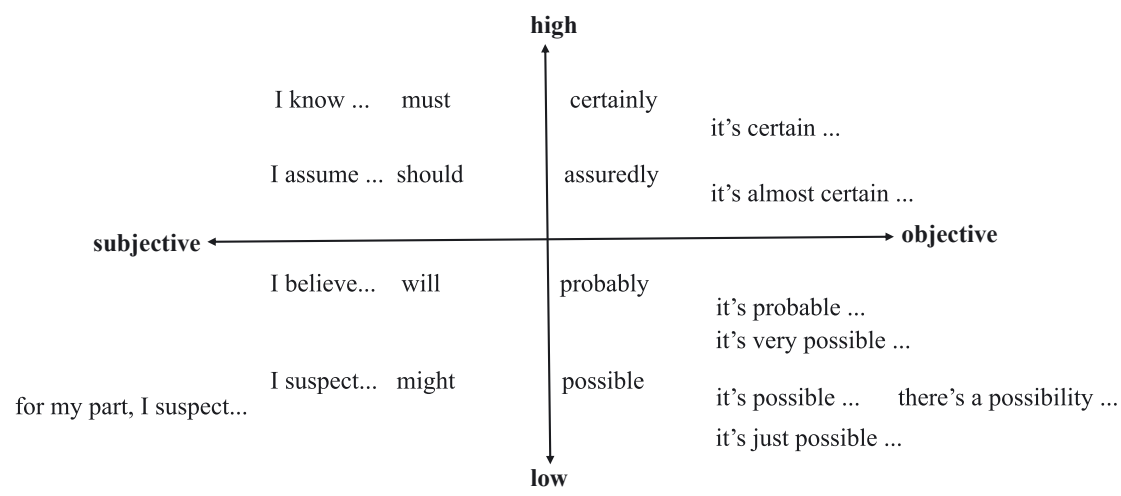

Figure 8: A topological perspective on value and orientation (Martin and Rose 2005: 17).

Accordingly, an overview of the modality system by Halliday is constructed in Figure 9.

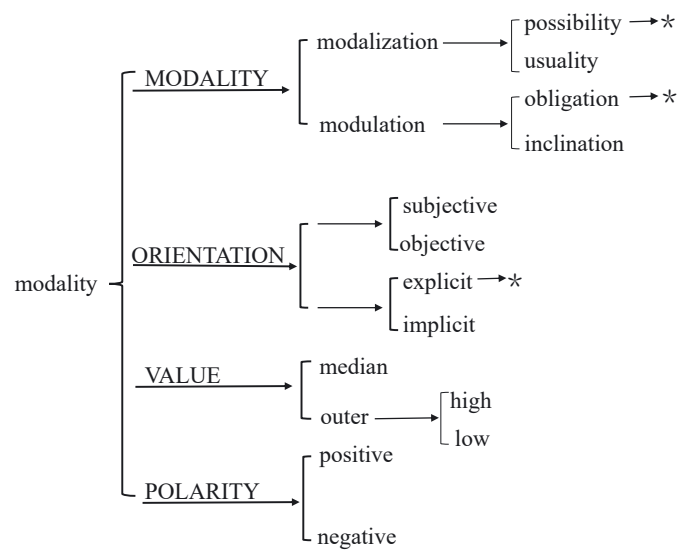

Figure 9: System of modality by Halliday and Matthiessen (2014: 182).

\section{Interpersonal modality revisited}

Interpersonal modality has been keeping explicable all these years since its first occurrence in 1970. The possible reason might be the fact that modalization in interpersonal modality is more or less equivalent to the proposition termed by other theories, and modulation is approximately equivalent to the event category. Nevertheless, the nuances between interpersonal modality and traditional or 
semantic map modality will become obvious if their subtypes are scrutinized and compared. The following two sections, therefore, explain in what way traditional studies of modality (Section 5.1) and the revised model of the semantic map (Section 5.2) are contributed to the revision of interpersonal modality in Halliday's sense.

\subsection{Inspiration of interpersonal modality from traditional senses}

The most obvious and significant feature in traditional studies of modality (cf. Figure 4) is that the concept of evidentiality has been regarded as one important subtype of proposition. Following this approach, I will also incorporate evidentiality into the subtype of the system of modalization in SFL. Modalization, by so doing, is classified into possibility, usuality and evidentiality. The reason for my inclusion of evidentiality into the modality is the fact that the scope of meanings that the evidentiality explores is in accordance with the definition of interpersonal modality by Halliday and Matthiessen (2014), i.e. the intermediate degrees between positivity and negativity. Italicized parts in Examples (8) and (9), exemplified for expounding the evidential meanings, meet this definition quite well. I think in Example (8) or clearly in Example (9) is only one of the many intermediate possibilities between yes and no. Furthermore, some phenomena pertinent to the scope of modal meanings, if we resort to the present system of interpersonal modality, cannot be expounded (cf. Example (2)). Therefore, for the purpose of making this phenomenon explicable, the construct of evidentiality is assigned a status in the system of interpersonal modality. In addition, a minor modification is made with respect to the evidentiality in Figure 4. Precisely, inference is employed to replace induction and deduction because the former is generally regarded as the superordinate of the latter two terms. Hence, the system of evidentiality does not look redundant and is reader-friendly.

With respect to possibility and necessity, the system of interpersonal modality in SFL and the system of modality in the traditional sense and modality's semantic map differ considerably in that the former explores them separately (cf. Figure 9) while the latter two investigate them in combination (cf. Figure 7). This combination of possibility and necessity leads to the partial ignorance of some epistemic and deontic meanings. By so doing, this serves the purpose very well in supplementing the areas that interpersonal modality in SFL misses the coverage.

The coverage of possibility under the system of modalization should be examined in more detail. In Halliday's system of modality, items denoting possibility are not clarified. Furthermore, a more cognitive effort is required to 
have a clear cut among these items under the scope of possibility. The studies about possibility in traditional and semantic map approaches have mainly touched upon the fields of epistemic and root possibility (non-epistemic and deontic possibility are employed by some scholars, but root possibility is preferred in this paper because language evolvement of modal meanings from root modals to epistemic modals is clearly suggested by the use of the word 'root'). For instance, may in the two clauses in Table 1 You may go to the US by ship and He may be in the office now. The first may expresses the societal permission or root possibility while the second expresses the meaning of epistemic possibility. Therefore, these exemplar clauses demonstrate that the contrast of possibility is presented. Besides, the research scope of inclination should be also specified. The classification of inclination into volition and ability is similar to that of possibility. Precisely, although the quasi-modal be willing to and modal auxiliary can are expressing the participants' inclination, they are different in that the former is volitional while the latter is ability oriented. It seems that can in Example (1) may be grouped into the subtype of ability, but the system does not distinguish internalization and externalization. Hence, it is of necessity to refer to the next section.

All factors being considered, the system network of interpersonal modality in Figure 9 is rewritten as Figure 10.

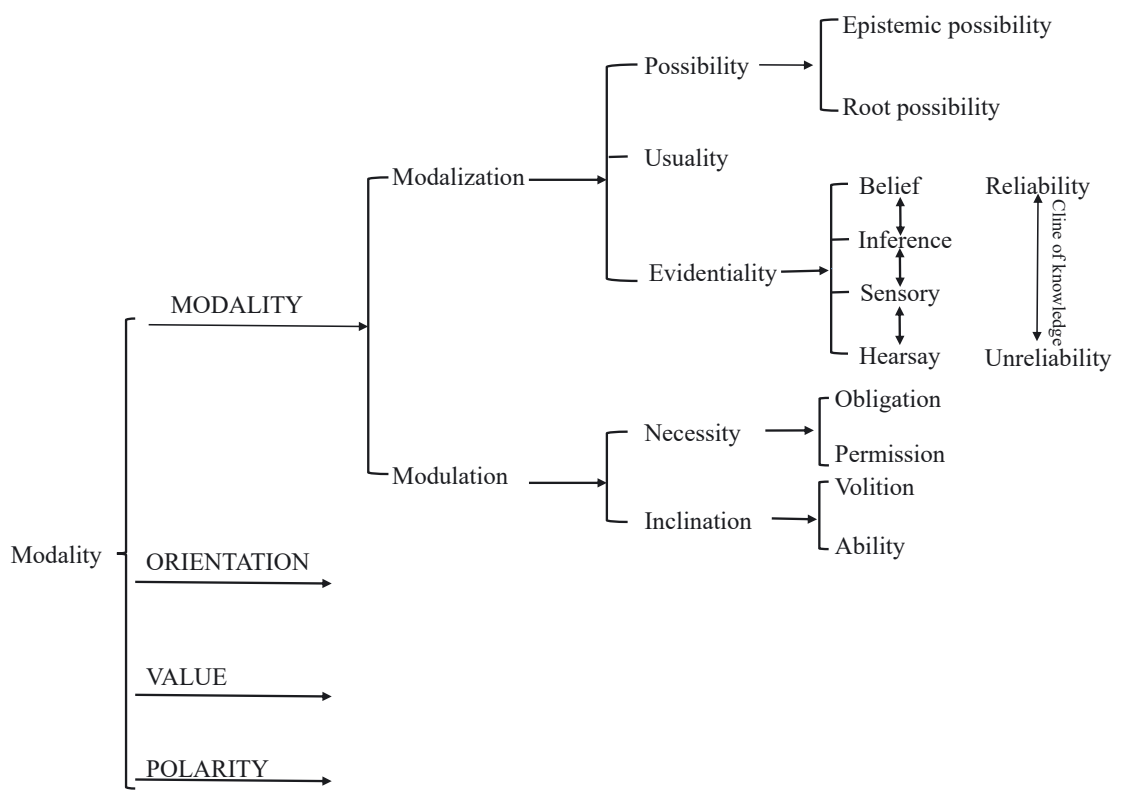

Figure 10: System of interpersonal modality - revised from traditional senses. 


\subsection{Inspiration of interpersonal modality from semantic maps of modality}

Studies concerning the semantic map of modality have been conducted in not only the categorization of the system of modality in delicacy, but also language evolvement of modal meanings. Inspired by Fan (2014), permission is further bifurcated into conditional permission and societal permission, and ability into external ability and internal ability. Up to now, can in Example (2) can be clarified as denoting the internal ability of participants. As for the evolution of modal meanings from root possibility to epistemic possibility or from inclination to necessity, a one-way arrowed line is applied to indicate the direction of evolvement.

Consequently, a full system of interpersonal modality in SFL is constructed and diagrammed in Figure 11.

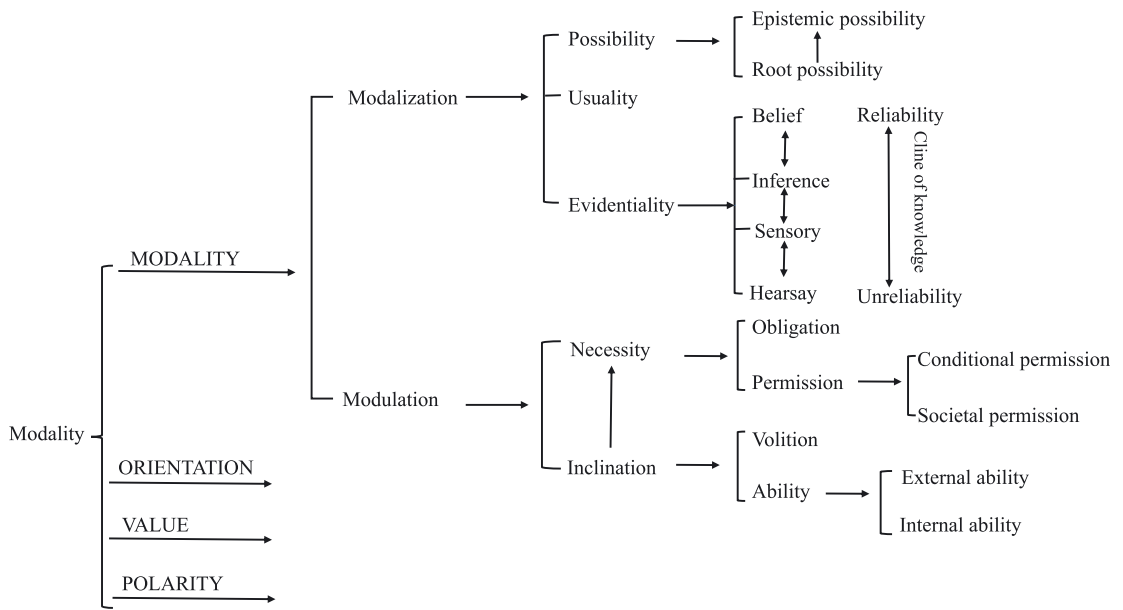

Figure 11: A full system of interpersonal modality in SFL.

\section{Conclusion}

Traditional approaches and theories of the semantic map on modality have contributed to revising the system of interpersonal modality in SFL very enormously. After a preliminary investigation of relevant findings, some suggestions are made to revisions of the present system of interpersonal modality. Firstly, modalization should incorporate evidentiality as its subtype and assign it equal status with possibility and usuality. Secondly, possibility, necessity (supplanting 
obligation), and inclination should be further clarified if delicacy is taken into considerations. Finally, evolvement of modal meanings from inclination to necessity or from root possibility to epistemic possibility should be conspicuously specified. Although this paper has revisited the system of interpersonal modality in these respects, the overlapping area between evidentiality and possibility (e.g. the I think projecting clause) is not explored considerably owing to limitations of the present classifying approach. Future researches are recommended to explore these overlapping areas from the perspective of interpersonal modality in SFL.

\section{References}

Aikhenvald, Alexandra Y. 2015. Evidentials: Their links with other grammatical categories. Linguistic Typology 19(2). 239-277.

Anderson, Lloyd. 1986. Evidentials, paths of change, and mental maps: Typologically regular asymmetries. In Chafe Wallace \& Johanna Nichols (eds.), Evidentiality: The linguistic coding of epistemology, 261-272. Norwood, N): Ablex Publishing Corporation.

Chafe, Wallace. 1986. Evidentiality in English conversation and academic writing. In Chafe Wallace \& Johanna Nichols (eds.), Evidentiality: The linguistic coding of epistemology, 261-272. Norwood, N): Ablex Publishing Corporation.

DeLancey, Scott. 2001. The mirative and evidentiality. Journal of Pragmatics 33(3). 369-382. Faller, Martina. 2017. Reportative evidentials and modal subordination. Lingua 186-187. 55-67. Fan, Wenfang. 2001. Yufa yinyu liyun yanjiu [A systemic-functional approach to grammatical metaphor]. Beijing: Foreign Language Teaching and Research Press.

Fan, Xiaolei. 2014. Yi “xuke - renshi keneng” zhi queshi lun yuyi ditu de xingshi he gongneng zhi xifen - Jianlun qingtai leixing xitong zhi xin jieding [Subdivision principles of form and function in semantic map based on the absence of path 'permission-epistemic possibility']. Shijie Hanyu Jiaoxue [Chinese Teaching in the World] 28(1). 18-35.

Fan, Xiaolei. 2017. Yuyi ditu de jiexidu ji biaozheng fangshi - Yi "nengliyi wei hexin de yuyi ditu" weili [Semantic map: Resolution and representation model]. Shijie Hanyu Jiaoxue [Chinese Teaching in the World] 31(2). 194-214.

Feng, Zongxin. 2011. Xitong gongneng yuyanxue zhong de qingtai xitong: Luoji, yuyi, yuyong [The system of modality in systemic functional linguistics: Logic, semantics and pragmatics]. Waiyu Jiaoxue [Foreign Language Education] 32(6). 1-10.

Halliday, Michael A. K. 1970. Functional diversity in language, as seen from a consideration of modality and mood in English. Foundations of Language 6(3). 322-361.

Halliday, Michael A. K. 1985. An introduction to functional grammar. London: Arnold.

Halliday, Michael A. K. 1994. An introduction to functional grammar, 2nd edn. London: Arnold.

Halliday, Michael A. K. \& Christian M. I. M. Matthiessen. 2004. An introduction to functional grammar, 3rd edn. London: Arnold.

Halliday, Michael A. K. \& Christian M. I. M. Matthiessen. 2014. Halliday's introduction to functional grammar, 4th edn. London: Routledge.

He, Ming \& Shaojie Zhang. 2019. Guowai qingtai yanjiu dui hanyu yuqi yanjiu de jiejian yu qishi [Implications of studies of modality abroad for the research on mood in Chinese]. Waiyu Jiaoxue [Foreign Language Education] 40(5). 13-17. 
Huang, Jinyi \& Jinjun Wang. 2021. Evidentiality in science from specialization to popularization: A case study of COVID-19 texts. Journal of World Languages 7(1). 124-155.

Larreya, Paul. 2009. Towards a typology of modality in language. In Raphael Salkie, Pierre Busuttil, Johan van der Auwera \& Larreya Paul (eds.), Modality in English: Theory and description, 9-31. Berlin: Mouton.

Lau, Monica Laura \& Johan Rooryck. 2017. Aspect, evidentiality, and mirativity. Lingua 186-187. 110-119.

Leech, Geoffrey. 2013. Where have all the modals gone? An essay on the declining frequency of core modal auxiliaries in recent standard English. In Juana I. Marín-Arrese, Marta Carretero, Jorge Arús Hita \& Johan van der Auwera (eds.), English modality: Core, periphery and evidentiality, 95-115. Berlin: Mouton.

Li, Renzhi. 2004. Modality in English and Chinese: A typological perspective. Boca Raton, Florida: Dissertation.com.

Li, Zhanzi. 2001. Xueshu huayu zhong renzhi xing qingtai de duochong renji yiyi yanjiu [Interpersonal meanings of epistemic modality in academic discourse]. Waiyu yu Waiyu Jiaoxue [Foreign Languages and Their Teaching] 33(5). 353-358.

Lyons, John. 1977. Semantics. Cambridge: Cambridge University Press.

Martin, James R. \& Peter R. R. White. 2005. The language of evaluation: Appraisal in English. London: Palgrave Macmillan.

McCready, Eric \& Norry Ogata. 2007. Evidentiality, modality and probability. Linguistics and Philosophy 30. 147-206.

Nuyts, Jan \& Johan van der Auwera (eds.). 2016. The Oxford handbook of modality and mood. Oxford: Oxford University Press.

Palmer, Frank R. 1986. Mood and modality. Cambridge: Cambridge University Press.

Palmer, Frank R. 1990. Modality and English modals. London: Longman.

Palmer, Frank R. 2001. Mood and modality, 2nd edn. Cambridge: Cambridge University Press.

Palmer, Frank R. 2003. Modality in English: Theoretical, descriptive and typological issues. In Roberta Facchinetti, Frank R. Palmer \& Manfred G. Krug (eds.), Modality in contemporary English, 1-17. New York: Mouton.

Portner, Paul. 2009. Modality. Oxford: Oxford University Press.

Roque, Lila San. 2019. Evidentiality. Annual Review of Anthropology 48. 353-370.

Salkie, Raphael. 2009. Degrees of modality. In Raphael Salkie, Pierre Busuttil \& Johan van der Auwera (eds.), Modality in English: Theory and description, 79-105. Berlin: Mouton.

Singh, Charanjit. 2019. Modality and ideology: A systemic functional linguistics study. Language in India 19(6). 56-65.

Smith, Nicholas. 2003. Changes in the modals and semi-modals of strong obligation and epistemic necessity in recent British English. In Roberta Facchinetti, Manfred Krug \& Frank Palmer (eds.), Modality in contemporary English, 241-266. Berlin: Mouton.

Sweetser, Eve E. 1990. From etymology to pragmatics: Metaphorical and cultural aspects of semantic structure. Cambridge: Cambridge University Press.

Tanverniers, Miriam. 2018. Grammatical metaphor and grammaticalization: The case of metaphor of modality. Functions of Language 25(1). 164-204.

van der Auwera, Johan, Petar Kehayov \& Alice Vittrant. 2009. Acquistive modals. In Lotte Hogeweg, Helen de Hoop \& Andrej L. Malchukov (eds.), Cross-linguistic semantics of tense, aspect, and modality, 271-302. Amsterdam: John Benjamins. 
van der Auwera, Johan \& Vladimir A. Plungian. 1998. Modality’s semantic map. Linguistic Typology 2(1). 79-124.

Verhulst, An, Ilse Depraetere \& Liesbet Heyvaert. 2013. Source and strength of modality: An empirical study of root should, ought to and be supposed to in present-day British English. Journal of Pragmatics 55. 210-225.

Yang, Bingjun. 2018. Interpersonal metaphor revisited: Identification, categorization, and syndrome. Social Semiotics 29(2). 186-203.

Yang, Yanning. 2013. A corpus-based study of interpersonal grammatical metaphor in spoken Chinese. Language Sciences 38(1). 1-21.

Zhu, Guanming. 2005. Qingtai yu hanyu qingtai dongci [Modality and Chinese modal auxiliaries]. Shandong Waiyu Jiaoxue [Shangdong Foreign Language Teaching] 26(2). 17-21. 